\title{
Development of bacteria foraging optimization algorithm for cell formation in cellular manufacturing system considering cell load variations
}

\begin{abstract}
The cellular manufacturing system (CMS) is considered as an efficient production strategy for batch type production. The CMS relies on the principle of grouping machines into machine cells and grouping machine parts into part families on the basis of pertinent similarity measures. The bacteria foraging optimization (BFO) algorithm is a modern evolutionary computation technique derived from the social foraging behavior of Escherichia coli bacteria. Ever since Kevin M. Passino invented the BFO, one of the main challenges has been the employment of the algorithm to problem areas other than those of which the algorithm was proposed. This paper investigates the first applications of this emerging novel optimization algorithm to the cell formation (CF) problem. In addition, for this purpose matrix-based bacteria foraging optimization algorithm traced constraints handling (MBATCH) is developed. In this paper, an attempt is made to solve the cell formation problem while considering cell load variations and a number of exceptional elements. The $\mathrm{BFO}$ algorithm is used to create machine cells and part families. The performance of the proposed algorithm is compared with a number of algorithms that are most commonly used and reported in the corresponding scientific literature such as $\mathrm{K}$-means clustering, the C-link clustering and genetic algorithm using a well-known performance measure that combined cell load variations and a number of exceptional elements. The results lie in favor of better performance of the proposed algorithm.
\end{abstract}

Keyword: Cellular manufacturing system; Cell formation; Cell load variations; Bacteria foraging optimization algorithm 